\section{AB0407 HIGH REMISSION RATES IN PATIENTS WITH RHEUMATOID ARTHRITIS USING BIOLOGICS UNDER A TREAT TO TARGET STRATEGY AND A COMPREHENSIVE DISEASE-MANAGEMENT MODEL FIVE YEAR FOLLOW-UP RESULTS FROM A REAL-LIFE SETTING}

Pedro Santos-Moreno ${ }^{1}$, Michael Cabrera ${ }^{2}$, Diana Buitrago-Garcia ${ }^{3}$, Eva Cardozo ${ }^{1}$ Ivania Ramirez ${ }^{1}$, Danny Gomez ${ }^{1}$, Edwin Castillo', Sandra Farietta ${ }^{1} .{ }^{1}$ Biomab Center for rheumatoid arthritis, Rheumatology, Bogotá, Colombia; ${ }^{2}$ BiomabCenter for rheumatoid arthritis, EHR administration, Bogotá, Colombia; ${ }^{3}$ Biomab Center for rheumatoid arthritis, Nursing research, Bogotá, Colombia

Background: Treat to target (T2T) strategy for rheumatoid arthritis (RA) aims to achieve remission or low disease activity. On the other hand, biological disease-modifying antirheumatic drugs (bDMARDs) have shown to be effective to achieve clinical remission or, at least, low disease activity in patients with RA. On the other hand, comprehensive healthcare programs have demonstrated good clinical outcomes in patients with chronic conditions.

Objectives: The aim of this study was to describe global change in Disease Activity Score 28 (DAS28) in patients receiving biological therapy during 5 years, and who were subjected to a multidisciplinary care program.

Methods: A descriptive cohort study was conducted. Medical records of patients from specialized in RA center were reviewed during 2015-2017; those patients were followed-up under T2T standards and a multidisciplinary approach. Clinical follow-up was designed by the authors according to DAS28 as follows: every 3-5 weeks (DAS28 > 5.1), every 7-9 weeks (DAS28 $\geq 3.1$ and $\leq 5.1$ ), and every $11-13$ weeks (DAS28 < 3.1). Tender joint count (TJC), swollen joint count (SJC) and DAS28 were measured on each visit. Therapy had to be adjusted with DAS28 > 3.2 unless patient's conditions don't permit it; we considered this follow-up type as implementation of a T2T strategy in patients with RA. Patients entered into a multidisciplinary program of care with periodic consultations not only to rheumatology but with a physiatrist, psychologist, physiotherapist, occupational therapy nutrition, and, a patient focused program. With a multidisciplinary model of care the patient is seen as a whole, and the expectation is to achieve the best results in the management of RA. We divided patients in four groups: remission (REM), low disease activity (LDA), moderate disease activity (MDA) and high disease activity (HDA) patients and the aim of the study was to look at what percentage of patients who were in moderate or severe disease activity reached a low disease activity or remission. Descriptive epidemiology was done, we calculated means, and standard deviations for continuous variables and categorical variables were presented as rates. We compared disease activity at base line and at the end of follow-up.

Results: 747 patients meet our inclusion criteria, $85 \%$ of our patients were women, median age was 57 years RIQ (50-64); The most prescribed bDMARD was certolizumab $25 \%$ followed by etanercept $14 \%$, tocilizumab $12 \%$, abatacept $12 \%$, golimumab $10 \%$ rituximab $8 \%$, adalimumab $7 \%$, infliximab $6 \%$ and Tofacitinib $6 \%$. At beginning $53 \%$ of patients were in moderate disease activity and, $25 \%$ in high disease activity while at the end of follow up $89 \%$ of patients had achieved remission. See Table 1. It was stablished statistical significance between changes in median DAS28 at beginning and, at the end of follow-up $(\mathrm{P}<0.05)$.

Table 1. Comparison of DAS28

\begin{tabular}{lcccc}
\hline ACTIVITY LEVEL & \multicolumn{2}{c}{ BASELINE } & \multicolumn{2}{c}{5 YEAR FOLLOW-UP } \\
\cline { 2 - 5 } & $\mathrm{n}$ & $\%$ & $\mathrm{n}$ & $\%$ \\
\hline REM & & & 653 & 88.60 \\
LDA & 177 & 23 & 37 & 5.02 \\
MDA & 388 & 53 & 47 & 5.97 \\
HDA & 182 & 24 & 3 & 0.41 \\
\hline
\end{tabular}

Conclusion: Biological therapy is effective for treating patients with RA, there was an evident global improvement of DAS28 in a cohort of RA patients. Also, our findings agree with other studies where T2T programs have shown improvements in disease activity in patients with RA. Thus, multidisciplinary T2T comprehensive healthcare programs should be widely implemented in patients with RA.

Disclosure of Interests: Pedro Santos-Moreno Grant/research support from: Dr Santos has received research grants from Janssen, Abbvie and UCB, Speakers bureau: $\operatorname{Dr}$ Santos has received speaker fees from Sanofi, Lilly, Bristol, Pfizer, Abbvie, Janssen and UCB, Michael Cabrera: None declared, Diana Buitrago-Garcia: None declared, Eva Cardozo: None declared, Ivania Ramirez: None declared, Danny Gomez: None declared, Edwin Castillo: None declared, Sandra Farietta: None declared
DOI: 10.1136/annrheumdis-2019-eular.6119

\section{AB0408 FIXED-INTERVAL VERSUS ON-DEMAND RETREATMENT STRATEGY WITH RITUXIMAB IN RHEUMATOID ARTHRITIS: A RETROSPECTIVE COHORT STUDY}

Lisa Schapink, Nathan den Broeder, Alfons den Broeder, Lise Verhoef. Sint Maartenskliniek, Department of Rheumatology, Ubbergen, Netherlands

Background: Rituximab (RTX), a monoclonal anti CD20 B-cell antibody is safe and effective in the treatment of Rheumatoid Arthritis (RA). The most optimal retreatment strategy in responding patients is still unclear. A recent study by Chatzidionysiou et al suggests that RTX retreatment with Fixed-Interval (FI) strategy is better than retreatment with an OnDemand (OD) strategy. [1] However, whether $\mathrm{FI}$ treatment strategy is also superior in a treat to target setting is not known.

At our centre (Sint Maartenskliniek, the Netherlands), patients were retreated with RTX using the FI strategy and the OD strategy, by discretion of the rheumatologist, and using treat to target of DAS28CRP $<2.9$ in all patients.

In the FI strategy, patients receive retreatment after a predefined fixed period, mostly every 6 months. In the OD strategy, patients receive retreatment in case they experience increase in disease activity. In our hospital, most of the OD strategy patients were switched to the FI strategy in 2014 based on best evidence at that time, enabling us to retrospectively compare effectivity of these strategies.

Objectives: To compare the effectivity of retreatment of RA patients with RTX following the FI or OD retreatment strategy.

Methods: Adult $(\geq 18)$ RA patients (clinical diagnosis) who started RTX treatment ( 1 or $2 \times 1000 \mathrm{mg}$ or $2 \times 500 \mathrm{mg}$ intravenous) between $1-1$ 2008 and 1-6-2016 and received at least 3 infusion cycles were included Patients were treated with either FI or OD strategy, or crossed over from $\mathrm{OD}$ to $\mathrm{FI}$. For on demand treatment, RTX retreatment could be planned at the daycare within 2-4 weeks.

Primary outcome was DAS28-CRP, secondary outcome was mean yearly dose of RTX. Baseline characteristics and follow up data (DAS28-CRP scores, information on RTX infusions, and steroid injections) were retrospectively extracted from patients' health records.

A linear mixed model was used to analyse the influence of the strategies on DAS28-CRP score. Time since start of RTX, calendar year, RTX dose, intra-articular (IA) or intramuscular (IM) steroid injection $<6$ weeks ago, concomitant csDMARD use at start of treatment and RF status were added to the model as fixed effects. Data was analysed using Stata 13.1

Table 1. Baseline patient characteristics

\begin{tabular}{lc}
\hline Age, mean (sd) & $59.6(12.4)$ \\
\hline Disease duration at RTX start, median (IQR) & $11(5-17)$ \\
csDMARD use at RTX start, $\mathrm{n}(\%)$ & $124(58 \%)$ \\
Rheumatoid factor positivity, $\mathrm{n}(\%)$ & $166(78 \%)$ \\
Anti-CCP positivity, $\mathrm{n}(\%)$ & $152(72 \%)$ \\
Baseline DAS28CRP, mean (sd) & $4.0(1.2)$ \\
Strategy, n (\%) & $154(72 \%)$ \\
Fixed interval & $25(12 \%)$ \\
On demand & $34(16 \%)$ \\
Both strategies &
\end{tabular}

Results: 213 patients were included. 154 following $\mathrm{FI}$ strategy, 25 following the OD strategy and 34 switching from OD to FI. Median duration of follow up was 38 months (IQR: 23-64), with a median number of 8 (IQR 5-12) DAS28-CRP measurements per patient. Patient characteristics are shown in Table 1. The OD strategy was not associated with higher DAS28-CRP score compared to FI strategy: adjusted difference was 0.09 DAS28-CRP point $(95 \% \mathrm{Cl}:-0.08$ to 0.26$)$. Regardless of used strategy, DAS28-CRP improved significantly both over year of treatment, and by time from the start of RTX treatment. Furthermore was rheumatoid factor positivity associated with an lower DAS28-CRP in all patients, with adjusted difference of $-0.37(95 \% \mathrm{Cl}$ : -0.60 to -0.14$)$. Average yearly RTX dose was $1899 \mathrm{mg} / \mathrm{yr}$ (SD: 604) under the FI strategy and $1740 \mathrm{mg} /$ yr (SD: 732$)$ under the OD strategy $(95 \% \mathrm{Cl}$ difference: -336 to $34 \mathrm{mg} /$ $\mathrm{yr}$ ).

Conclusion: Retreatment of RA patients with a fixed interval strategy does not seem to lead to better disease control or more drug use com pared to an on demand strategy. A possible explanation might be the use of treat to target in our centre. Our study suggests that either strategy might be chosen in shared decision making and following treat to target. 
REFERENCES

[1] Chatzidionysiou, et al. J Rheumatol. 2017 Feb;44(2):162-169.

Disclosure of Interests: None declared DOI: 10.1136/annrheumdis-2019-eular.6215

\section{AB0409 B CELLS PROFILE AS A BIOMARKER FOR EARLY IDENTIFICATION OF OPTIMAL RESPONDERS TO TNF INHIBITORS IN RHEUMATOID ARTHRITIS}

Cristina Sobrino ${ }^{1}$, Borja Hernández-Breijo², Carlota García-Hoz ${ }^{3}$, Israel NietoGañán $^{3}$, Victoria Navarro-Compán ${ }^{2}$, Ana Martínez-Feito ${ }^{2}$, Javier Bachiller-Corral $^{1}$, Gemma Bonilla ${ }^{2}$, Paloma Lapuente-Suanzes ${ }^{3}$, Cristina Pijoan Moratalla ${ }^{1}$, Dora Pascual-Salcedo ${ }^{2}$, Alejandro Balsa ${ }^{2}$, Garbiñe Roy ${ }^{3}$, Mónica Vázquez $^{1}$, Luisa María Villar ${ }^{3}$, Chamaida Plasencia ${ }^{2}$, Eulalia Rodríguez-Martín ${ }^{3} .{ }^{1}$ Rheumatology Department. Ramón y Cajal University Hospital, IRYCIS., Madrid, Spain; ${ }^{2}$ ImmunoRheumatology Research Group, IdiPaz. La Paz University Hospital., Madrid, Spain; ${ }^{3}$ Immunology Department. Ramón y Cajal University Hospital, IRYCIS., Madrid, Spain

Background: The most common biological agents used as disease-modifying treatment in rheumatoid arthritis (RA) are TNF inhibitors (TNFi). Although these new strategies to treat RA have improved the course of the disease, approximately $30-50 \%$ of patients do not respond to this therapy. Early identification of optimal responders is crucial in the clinical setting.

Objectives: The aim of this study was to investigate if baseline percentages of different leukocyte subsets in peripheral blood (PBMCs) can contribute to identify RA patients who will respond to TNFi.

Methods: This was a prospective bi-center pilot study including 100 RA patients under TNFi therapy. Clinical activity was assessed at baseline and 6 months of treatment by disease activity score 28 (DAS28), considering optimal responders if they reached remission at 6 months (DAS28 $\leq 2.6)$. PBMCs were obtained before treatment and different leukocyte subsets were evaluated by flow cytometry (FACSCantoll instrument). The association between the percentage of PBMCs at baseline and clinical response at 6 months was evaluated through logistic regression models (odds ratio; $95 \% \mathrm{Cl}$ ). All the analyses were adjusted by sex, age, disease duration, concomitant methotrexate, baseline DAS28 and seropositivity (ACPA and/or RF).

Results: Demographic characteristics are shown in Table 1. After $6 \mathrm{~m}$ of TNFi treatment, $40 \%$ of the patients achieved clinical remission. A significant association between higher percentage of total $B$ cells $(O R=1.19$; $95 \%$; Cl:1.05-1.35; $\mathrm{p}=0.007$ ) and naive $\mathrm{B}$ cells (Bn; OR=1,32; 95\%; IC:1.08-1.61; $\mathrm{p}=0.007)$ at baseline and clinical response was found. The other PBMC subsets (monocytes, NK cells, CD4+ and CD8+ T cells subtypes) did not show statistical differences (Figure 1).

Conclusion: Our results suggest that basal B cells profile may contribute to identify optimal responders to TNFi in RA. (Funding: ISCIII (PI16/ 01092, Pl16/00474).

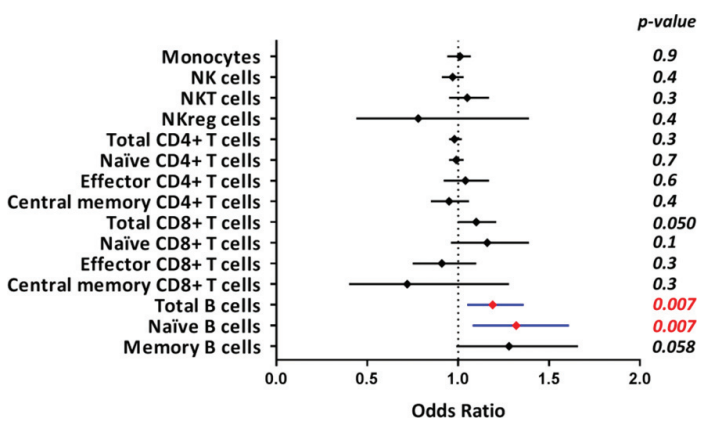

Figure 1. legend: Association between the percentage of PBMC subset before TNFi and the clinical remission. Multivariate logistic regression analysis was performed for each PBMC subset. The percentage of total B cells and in naïve B cells were independently associated with the clinical response. No association was found in other PBMC subsets. The analyses were adjusted by sex, age, disease duration, concomitant-methotrexate, seropositivity and baseline-DAS28.

\begin{tabular}{|c|c|}
\hline Baseline patients' characteristics & Total patients $(n=100)$ \\
\hline Age (years); mean $\pm S D$ & $53 \pm 13$ \\
\hline Female; $\mathbf{n}(\%)$ & $84(84)$ \\
\hline Disease duration (years); median (IQR) & $8(4-12)$ \\
\hline Rheumatoid factor positive; $\mathbf{n}(\%)$ & $77(77)$ \\
\hline ACPA positive; $n$ (\%) & $83(83)$ \\
\hline \multicolumn{2}{|l|}{ Smoking habit; n (\%) } \\
\hline no & $46(46)$ \\
\hline smoker & $20(20)$ \\
\hline ex-smoker & $34(34)$ \\
\hline Body mass index $\left(\mathrm{kg} / \mathrm{m}^{2}\right)$; median (IQR) & $24.8(22.9-29.6)$ \\
\hline DAS28; mean $\pm S D$ & $4.8 \pm 1.2$ \\
\hline CRP (mg/L); median (IQR) & $5.7(2.2-12.4)$ \\
\hline Previous TNFi treatment; $\mathbf{n}(\%)$ & $13(13)$ \\
\hline \multicolumn{2}{|l|}{ TNFi type; $n$ (\%) } \\
\hline Monoclonal antibodies & $55(55)$ \\
\hline Etanercept & $45(45)$ \\
\hline TNFi monotherapy & $4(4)$ \\
\hline Concomitant csDMARD; $\mathrm{n}(\%)$ & $96(96)$ \\
\hline OnlyMethotrexate (MTX) & $51(51)$ \\
\hline OnlyothercsDMARDs $(O D)^{*}$ & $18(18)$ \\
\hline$M T X+O D$ & $27(27)$ \\
\hline Prednisone; $\mathrm{n}(\%)$ & $57(57)$ \\
\hline
\end{tabular}

Table1

Disclosure of Interests: Cristina Sobrino: None declared, Borja Hernández-Breijo: None declared, Carlota García-Hoz: None declared, Israel Nieto-Gañán: None declared, Victoria Navarro-Compán: None declared ANA MARTÍNEZ-FEITO: None declared, Javier Bachiller-Corral: None declared, Gemma Bonilla: None declared, Paloma Lapuente-Suanzes: None declared, Cristina Pijoan Moratalla: None declared, DORA PASCUAL-SALCEDO Grant/research support from: Pfizer, Speakers bureau: Pfizer, Abbvie, Takeda, Alejandro Balsa Grant/research support from: Abbvie, Pfizer, Novartis, BMS, Nordic, Sanofi, Consultant for: Abbvie, Pfizer Novartis, BMS, Nordic, Sanofi, Sandoz, Lilly, Paid instructor for: Pfizer, Speakers bureau: Pfizer, Novartis, UCB, Nordic, Sanofi, Sandoz, Lilly, Garbiñe Roy: None declared, Mónica Vázquez: None declared, Luisa María Villar: None declared, Chamaida Plasencia Speakers bureau: Pfizer, MSD, Eulalia Rodríguez-Martín: None declared

DOI: 10.1136/annrheumdis-2019-eular.4730

\section{AB0410 DISCONTINUATION OF ORAL GLUCOCORTICOID AFTER INITIATION OF BIOLOGICAL DMARD DUE TO A HIGHER DOSE OF METHOTREXATE; A RETROSPECTIVE OBSERVATIONAL STUDY BASED ON DATA FROM A JAPANESE MULTICENTER REGISTRY STUDY}

Mochihito Suzuki, Toshihisa Kojima, Nobunori Takahashi, Naoki Ishiguro. Nagoya University Graduate School of Medicine, Orthopedics, Nagoya, Japan

Background: In the treatment of rheumatoid arthritis, glucocorticoid that provide anti-inflammatory effects in the early stage of treatment is an important drug. We recommend discontinuing of glucocorticoid as much 